\title{
Changing shapes and implied viscosities of suspended submicron particles
}

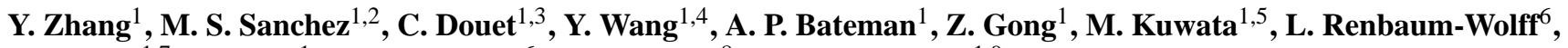

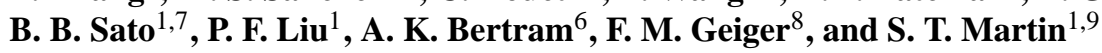 \\ ${ }^{1}$ School of Engineering and Applied Sciences, Harvard University, Cambridge, Massachusetts, USA \\ ${ }^{2}$ Department of Chemical Engineering, University of São Paulo, São Paulo, Brazil \\ ${ }^{3}$ Department of Energy and Environment, National Institute of Applied Science of Lyon, Villeurbanne, France \\ ${ }^{4}$ School of Public Health, Harvard University, Boston, Massachusetts, USA \\ ${ }^{5}$ Earth Observatory of Singapore, School of Physical and Mathematical Sciences, College of Sciences, Nanyang \\ Technological University, Singapore, Singapore \\ ${ }^{6}$ Department of Chemistry, University of British Columbia, Vancouver, British Columbia, Canada \\ ${ }^{7}$ Department of Chemical Engineering, Federal University of Sao Carlos, Sao Carlos, São Paulo, Brazil \\ ${ }^{8}$ Department of Chemistry, Northwestern University, Evanston, Illinois, USA \\ ${ }^{9}$ Department of Earth and Planetary Sciences, Harvard University, Cambridge, Massachusetts, USA
}

Correspondence to: S. T. Martin (scot_martin@harvard.edu) and F. M. Geiger (geigerf@chem.northwestern.edu)

Received: 26 January 2015 - Published in Atmos. Chem. Phys. Discuss.: 9 March 2015

Revised: 17 June 2015 - Accepted: 29 June 2015 - Published: 16 July 2015

\begin{abstract}
The change in shape of atmospherically relevant organic particles is used to estimate the viscosity of the particle material without the need for removal from aerosol suspension. The dynamic shape factors $\chi$ of particles produced by $\alpha$-pinene ozonolysis in a flow tube reactor, under conditions of particle coagulation, were measured while altering the relative humidity $(\mathrm{RH})$ downstream of the flow tube. As relative humidity was increased, the results showed that $\chi$ could change from 1.27 to 1.02 , corresponding to a transition from aspherical to nearly spherical shapes. The shape change could occur at elevated RH because the organic material had decreased viscosity and was therefore able to flow to form spherical shapes, as favored by the minimization of surface area. Numerical modeling was used to estimate the particle viscosity associated with this flow. Based on particle diameter and RH exposure time, the viscosity dropped from $10^{(8.7 \pm 2.0)}$ to $10^{(7.0 \pm 2.0)} \mathrm{Pa}$ (two sigma) for an increase in RH from $<5$ to $58 \%$ at $293 \mathrm{~K}$. These results imply that the equilibration of the chemical composition of the particle phase with the gas phase can shift from hours at mid-range $\mathrm{RH}$ to days at low RH.
\end{abstract}

\section{Introduction}

Volatile organic compounds emitted by the biosphere, as well as from anthropogenic activities, react in the atmosphere with oxidants to produce secondary, oxygenated species (Fehsenfeld et al., 1992; Hallquist et al., 2009). Some of these products ultimately contribute to the mass concentration of the atmospheric particle population, as so-called secondary organic material (SOM) (Hallquist et al., 2009). Atmospheric particles have important effects on both climate and human health, among other topics (Seinfeld and Pandis, 2006), although the mechanisms of action remain incompletely understood both qualitatively and quantitatively. Recently, the viscosity and the diffusivity of SOM have emerged as important topics (Vaden et al., 2010; Virtanen et al., 2010; Abramson et al., 2013; Hosny et al., 2013; Pajunoja et al., 2013; Power et al., 2013; Renbaum-Wolff et al., 2013; Bateman et al., 2015; Kidd et al., 2014; Wang et at., 2014). These properties influence whether gases and the dynamic interplay between atmospheric particles are confined to the surface region of a particle or alternatively can proceed to the interior (Shiraiwa et al., 2013a, 2014), with potential important consequences for the growth, the reactivity, and ultimately the fate 
of atmospheric organic particles. Diffusivity of a species and the viscosity of the host matrix are typically quantitatively related to one another, often through the Stokes-Einstein relationship (Lindsay, 2009).

Until recently, SOM was modeled as a low-viscosity liquid into which gas-phase species from the surrounding environment diffuse quickly and for which the chemical gasparticle equilibrium is rapidly reached (Donahue et al., 2006; Hallquist et al., 2009). More recent work, however, has indicated that viscosities are higher and diffusion coefficients are lower than would be consistent with a liquid material (Vaden et al., 2010; Virtanen et al., 2010; Cappa and Wilson, 2011; Perraud et al., 2012; Abramson et al., 2013; Renbaum-Wolff et al., 2013; Kidd et al., 2014; Wang et at., 2014; Price et al., 2015). An underestimated viscosity and hence overestimated diffusion coefficient can result in an overprediction of particle mass concentrations as well as an underprediction of gasphase concentrations (Shiraiwa and Seinfeld, 2012). Particle reactivity (Shiraiwa et al., 2011; Kuwata and Martin, 2012a; Zelenyuk et al., 2012; Zhou et al., 2013; Slade and Knopf, 2014), number concentrations (Riipinen et al., 2011), and diameters (Shiraiwa et al., 2013b) can also be influenced by viscosities and diffusion rates, in turn influencing model predictions related to air quality and climate.

A challenge in the study of SOM is that properties can change upon removal of the SOM from particle suspension, whether by deposition on a substrate, extraction in water, study in vacuum, or a combination of all three, because of the semivolatile nature of SOM. Another further challenge for studying and understanding SOM is that it has a dynamic hygroscopic response to relative humidity, meaning that water is taken up and released with cycles in RH (Varutbangkul et al., 2006). The properties of organic particles, including viscosity, change with the fractional water content in the material (Zobrist et al., 2011; Renbaum-Wolff et al., 2013; Shrestha et al., 2014; Wang et al., 2014). Even so, advances on these challenges are needed because SOM in the atmosphere occurs in the aerosol form, and the surrounding environment in the planetary boundary layer regularly undergoes cycling between low and high RH, implying a dynamic state in the viscosity of SOM that is not well understood or quantified at present.

The present study estimates the viscosity of SOM in aerosol form as suspended submicron particles. By comparison, the diffusivity of SOM in aerosol form has been studied by the uptake or release of tracer species into suspended SOM particles (Kuwata and Martin, 2012a; Abramson et al., 2013; Loza et al., 2013; Robinson et al., 2013; Saleh et al., 2013; Zhou et al., 2013). The experimental strategy of the present study is to first evolve a particle population by self-coagulation, second, to select a small subset $(<0.25 \%)$ of highly aspherical particles from the overall population, and third, to observe the tendency of the aspherical particles to adjust to spherical shapes as a function of $\mathrm{RH}$ and exposure time. Viscosity is inferred from the rate of shape change. Particle shape is quantitatively defined by aerodynamic behavior. The dynamic shape factor $\chi$ is the ratio of the drag force on an actual particle divided by the drag force experienced by a volume-equivalent sphere (Wang et al., 2010). Shape factors of nearly spherical particles approach unity whereas highly aspherical particles have significantly larger shape factors, with an exception not applicable to the present study in the case of aerodynamic design such as bullets oriented parallel to flow streamlines. As the viscosity of the particle material decreases upon exposure to elevated RH, flow occurs and the particle shapes approach sphericicity in order to minimize surface area. A numerical simulation, using the tools of computational fluid dynamics and taking into account particle size and exposure time to elevated $\mathrm{RH}$, is used to determine the material viscosity that is required to bring closure between modeled and observed RH-dependent changes in shape factor, by optimization. The numerical simulation extends in several ways, introduced by Renbaum-Wolff et al. (2013), who modeled the flow of substrate-supported particles. In addition to the results presented here, it is expected that the general method can be applied more broadly across other disciplines which seek to determine the viscosity of material bodies in the key size ranges of nanotechnologies and biological sciences (i.e., from $<10 \mathrm{~nm}$ up to several microns).

\section{Experimental}

\subsection{Flow tube reactor}

The production of SOM particles in the flow tube reactor largely followed the procedures described in Shrestha et al. (2013). Additional information on materials and methods is presented in Sect. S2 of the Supplement. Briefly, because particles were produced from the homogeneous nucleation of supersaturated organic vapors, a temperature control of $293.0 \pm 0.1 \mathrm{~K}$ across 12 to $24 \mathrm{~h}$ for individual experiments was necessary for reproducible particle numberdiameter distributions. The flow tube and the associated gas-flow systems were therefore housed in a temperaturecontrolled, double-walled, water-jacketed stainless steel box (Fig. S2 in the Supplement). Ozone and $\alpha$-pinene concentrations of the different experiments are listed in Table 1. The relative humidity was $<5 \%$. The aerosol flowing out of the reactor was passed through an ozone diffusion scrubber, which reduced ozone concentrations sufficiently to curtail further SOM production and thus to provide a well-defined reaction time. The aerosol subsequently flowed into either a 0.9 or $6.6 \mathrm{~L}$ flask for an average residence time of 45 or $310 \mathrm{~s}$, respectively, during which additional particle coagulation took place at various RH. The aerosol flow continued into a region of $\mathrm{RH}$ control. The apparatus for adjusting $\mathrm{RH}$, including exposure time, consisted of a Nafion RH conditioner (Perma Pure, Model PD-200T-12) to set the RH of 
Table 1. Summary of experimental conditions.

\begin{tabular}{|c|c|c|c|c|c|c|}
\hline & \multirow[t]{3}{*}{ Experiment } & \multicolumn{4}{|c|}{ Flow tube SOM generation } & \multirow{3}{*}{$\begin{array}{c}\text { Relative humidity } \\
\qquad(\%)\end{array}$} \\
\hline & & \multicolumn{2}{|c|}{ Precursor conditions $^{\mathrm{a}}$} & \multicolumn{2}{|c|}{ Particle conditions ${ }^{b}$} & \\
\hline & & $\begin{array}{c}\alpha \text {-Pinene } \\
\text { (ppb) }\end{array}$ & $\begin{array}{l}\text { Ozone } \\
(\mathrm{ppb})\end{array}$ & $\begin{array}{c}\text { Number } \\
\text { conc. }\left(\mathrm{m}^{-3}\right)\end{array}$ & $\begin{array}{l}\text { Mode diam- } \\
\text { eter }\left(10^{-9} \mathrm{~m}\right)\end{array}$ & \\
\hline \#1 & Mid. concentration & $700 \pm 7$ & $14.0 \pm 0.2$ & $(2.9 \pm 0.2) \times 10^{11}$ & $63 \pm 3$ & $<3$ \\
\hline \#2 & Mid. concentration & $700 \pm 7$ & $13.8 \pm 0.2$ & $(2.9 \pm 0.2) \times 10^{11}$ & $66 \pm 3$ & $6-100^{\mathrm{d}}$ \\
\hline \#3 & Mid. concentration & $700 \pm 7$ & $24.6 \pm 0.8$ & $(5.4 \pm 0.3) \times 10^{11}$ & $80 \pm 3$ & $4-82$ \\
\hline \#4 & Mid. concentration & $700 \pm 7$ & $30.3 \pm 0.5$ & $(4.8 \pm 0.4) \times 10^{11}$ & $80 \pm 6$ & $4-82$ \\
\hline \#5 & High concentration & $1000 \pm 10$ & $13.0 \pm 0.2$ & $(4.3 \pm 0.2) \times 10^{11}$ & $111 \pm 2$ & $4-54$ \\
\hline \#6 & AMS experiment & $500 \pm 5$ & $13.0 \pm 0.2$ & $(2.6 \pm 0.2) \times 10^{11}$ & $68 \pm 3$ & 4-94 \\
\hline \#7 & Mid concentration & $700 \pm 7$ & $14.8 \pm 0.2$ & $(3.4 \pm 0.3) \times 10^{11}$ & $85 \pm 3$ & $4-58$ \\
\hline
\end{tabular}

${ }^{a}$ Concentrations at inlet of flow tube reactor. ${ }^{b}$ Concentrations in the outflow of the reactor, as measured by SMPS. ${ }^{\mathrm{c}}$ Range of relative humidities studied in stepwise fashion in series of experiments. The overall $\mathrm{RH}$ cycle was $(<5 \% \mathrm{RH}) \rightarrow(\mathrm{RH}$ value from within range shown in table $) \rightarrow(<5 \% \mathrm{RH})$.

Uncertainties correspond to one sigma. ${ }^{\mathrm{d}}$ For $100 \% \mathrm{RH}$, a flask of water was slightly heated until condensation was apparent on the walls.

the aerosol flow, followed by a 0.9 or $6.6 \mathrm{~L}$ flask to serve as a plenum for RH exposure (i.e., 45 or $310 \mathrm{~s}$, respectively), followed by two diffusion dryers and a second Nafion RH conditioner to reset $\mathrm{RH}$ to $<5 \%$.

\subsection{Particle mobility diameter and particle mass}

Exiting the RH control system, the aerosol flow was divided into two streams (Fig. S2 in the Supplement). The first stream was sampled by a Differential Mobility Analyzer (DMA) (TSI model 3081) (Knutson and Whitby, 1975). The DMA outflow consisted of a subpopulation of particles with a central electric mobility diameter. The central diameters of the different experiments are listed in Table 1. The DMA outflow was sampled by an Aerosol Particle Mass Analyzer (APM) (APM-3600, KANOMAX Inc.) (Ehara et al., 1996), and the particle number concentration in the APM outflow was measured by a Condensation Particle Counter (CPC; TSI model 3022a) (Agarwal and Sem, 1980). The APM voltage was scanned at fixed rotation speed to measure the number-mass distribution of the particle population (Kuwata and Kondo, 2009). The second flow stream from the reactor outflow was sampled by a Scanning Mobility Particle Sizer (SMPS; TSI, model 3071A; CPC; TSI, model 3772) to characterize the number-diameter distribution of the produced particle population (Hoppel, 1978). The DMA, APM, and SMPS were regularly calibrated using aerosol particles of polystyrene latex (PSL) or ammonium sulfate, both of which were produced by nebulization (Model 3076, TSI Corporation) (Biskos et al., 2008).

\section{Results and discussion}

\subsection{Coagulation and dynamic shape factors}

An aerosol population of SOM particles was produced in a flow tube using 500, 700, and $1000 \mathrm{ppb}$ of (+)- $\alpha$-pinene and 12 to $30 \mathrm{ppm}$ of ozone for $<5 \% \mathrm{RH}$ at $1 \mathrm{~atm}$. The number concentrations and mode diameters are listed in Table 1 for $<5 \% \mathrm{RH}$. Because the concentrations were high in the flow tube, coagulation occurred. Depending on the numberdiameter distribution and the reactor residence time, this resulted in several types of coagulated particles being formed. Scanning electron micrographs are shown in Fig. 1 (cf. column 1). The smallest features apparent in the images of column 1 are on order of 5 to $10 \mathrm{~nm}$ and represent the primary nucleated particles in the flow tube. These nanoparticles coagulated in the flow tube to larger particles on order of 20 to $40 \mathrm{~nm}$ that then exit the flow tube. Each of these particles is referred to as a monomer and is represented by a red circle in the images in Fig. 1. After the flow tube, there was a retention volume in which additional coagulation of the monomers occurred. Dimers, trimers, and high-order agglomerates formed from monomer coagulation (images A1, B1, and C1, respectively). The dimers and trimers, having aspherical shapes at $<5 \%$ RH and making up $<0.25 \%$ of the total particle population (cf. Fig. S1), constituted the core of the experimental strategy.

The instrumental approach for characterizing the shapes of the suspended particles consisted of a DMA (Knutson and Whitby, 1975) coupled to an APM (Ehara et al., 1996) (Fig. S2). The DMA was used to select a subpopulation of controlled mobility diameters from the overall particle population. The number-mass distribution of this subpopulation was then measured using the APM. The dimensionless dynamic shape factor $\chi$ was then calculated as follows 


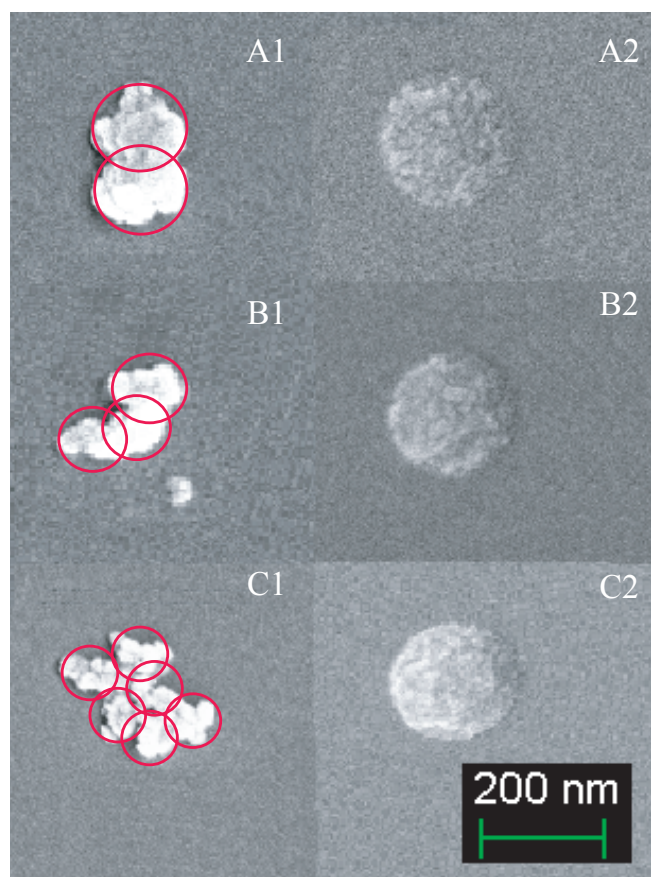

Figure 1. SEM images of the particles obtained from $700 \mathrm{ppb} \alpha$ pinene and sampled for a central mobility diameter of $180.0 \mathrm{~nm}$. The aerosol particles were collected on the silica substrate for $12 \mathrm{~h}$ and then coated with $5 \mathrm{~nm}$ of $\mathrm{Pt} / \mathrm{Pd}$. The voltage for the electron beam was $5 \mathrm{kV}$, and the working distance was $2.3 \mathrm{~mm}$. Column 1 shows dimer, trimer, and higher-order agglomerates of the granular monomers for $<5 \% \mathrm{RH}$. Red circles identify the monomers. Column 2 shows nearly spherical particles that were collected after exposure to $80 \% \mathrm{RH}$ followed by drying to $<5 \% \mathrm{RH}$.

(Sect. S1) (Kuwata and Kondo, 2009):

$$
\chi=\frac{d_{\mathrm{m}}}{\left(6 m_{\mathrm{p}} / \pi \rho\right)^{1 / 3}} \frac{C_{\mathrm{C}}\left(\left(6 m_{\mathrm{p}} / \pi \rho\right)^{1 / 3}\right)}{C_{\mathrm{C}}\left(d_{\mathrm{m}}\right)}
$$

for particle mass $m_{\mathrm{p}}$, mobility diameter $d_{\mathrm{m}}$, and material density $\rho$. A material density of $1.2 \times 10^{3} \mathrm{~kg} \mathrm{~m}^{-3}$ was used. The Cunningham slip correction factor is given by $C_{\mathrm{C}}$. The values $d_{\mathrm{m}}$ and $m_{\mathrm{p}}$ were taken as the central values of the DMA setting and the APM measurement, respectively. Instrument calibration and employed material densities are discussed in Sects. S2 and S3. The $\chi$ value of spheres is unity whereas that of submicron dimer and trimer particles ranges from 1.03 to 1.16 and 1.12 to 1.28 , respectively, in the transition regime (i.e., Knudsen number from 0.1 to 10) (Hochrainer and Hanel, 1975; Hansson and Ahlberg, 1985; Kousaka et al., 1996; Zelenyuk et al., 2006).

Examples of the number-mass distributions recorded in three replicate experiments are shown in Fig. 2. The DMA was set to select only the large-diameter particles in the tail of number-diameter distribution of the particle population (cf. Fig. S1). The selected particle subpopulation had a central mobility diameter of $126.0 \mathrm{~nm}$ compared to a mode diameter of $52.0 \mathrm{~nm}$ in the original population, which had 0.1 and

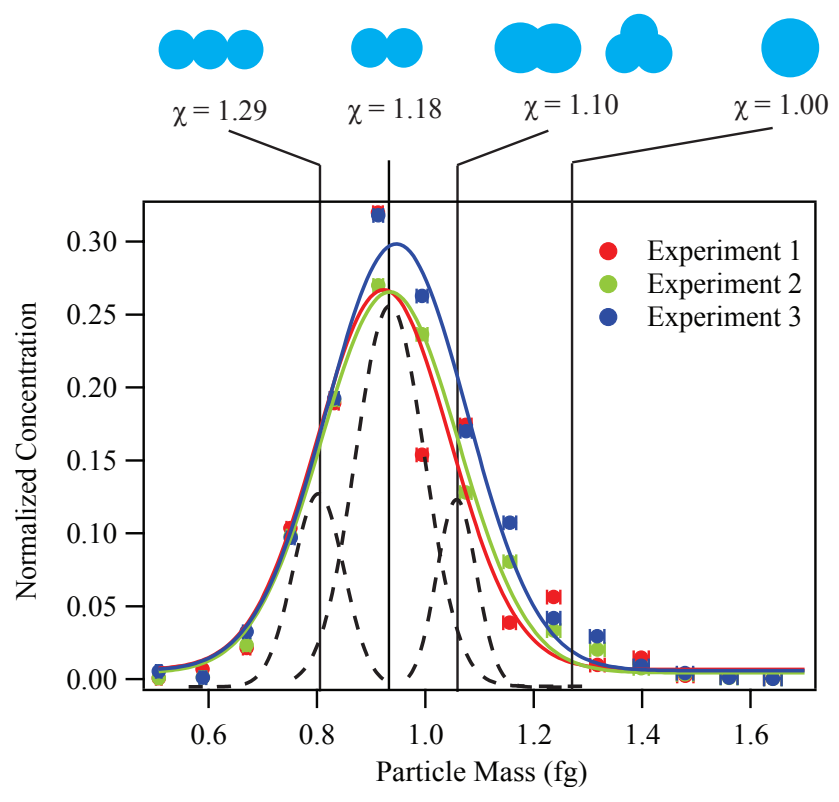

Figure 2. An example of the number-mass distribution, as measured using the DMA-APM system. Results of three replicate experiments are shown to demonstrate reproducibility. Two-sigma uncertainty is represented by the error bars, which are approximately the same size as the data markers. The lines represent fits of a normal distribution to the data. The abscissa is calculated based on the APM rotation speed and the voltage applied between the walls of the APM cylinders. Dynamic shape factors calculated by Eq. (1) using $m_{\mathrm{p}}$ and $d_{\mathrm{m}}$ are indicated by the vertical lines. The particles shown in the plot were produced from $700 \mathrm{ppb} \alpha$-pinene and $14 \mathrm{ppm}$ ozone. A central mobility diameter of $126.0 \mathrm{~nm}$ was selected by the DMA. The width of the DMA-APM instrument train is represented by the dashed lines.

$99.9 \%$ diameter intervals of 20.2 and $151.2 \mathrm{~nm}$, respectively (cf. Fig. S1). Contributions from monomers, as well as from dimers of disparate monomer sizes (e.g., one large + one small) and other higher-order agglomerates, were therefore absent in the analyzed data sets. Although doubly charged particles were present in the outflow of the DMA, the mass range covered in Fig. 2 corresponds only to singly charged particles.

As a result of these filtering strategies, the subpopulation represented in Fig. 2 consisted of singly charged dimer, trimer, and higher-order agglomerates. By use of Eq. (1), the dynamic shape factor of particles at the central value of the number-mass distribution was 1.18. Examples of the intrinsic width of the DMA-APM instrument train are denoted by the three dashed curves. The data are seen to be wider than the instrumental width. The subpopulation, therefore, consisted of particles having a quasi-monodisperse mobility diameter yet a range of dynamic shape factors, corresponding to a variety of different types of coagulated aspherical particles. Vertical lines are shown for $\chi$ values at 1.10 and 1.29, in addition to the central value of 1.18 as well as a reference 
value of 1.0. Diagram representations of some examples of the types of particles that may be associated with the shape factors are represented as insets in the figure. Section S4 presents additional data concerning the dependence of $\chi$ on the variability of synthesis conditions of the agglomerate particles as well as on the DMA-selected mobility diameter.

\subsection{Effects of relative humidity}

The particle populations of dimer, trimer, and higher-order agglomerates produced at low RH were subsequently exposed to elevated RH for a controlled residence time. At sufficiently high $\mathrm{RH}$, the particle material flowed. The micrographs of column 2 in Fig. 1 show that nearly spherical particles resulted from exposure to sufficiently high RH. Correspondingly, this resulted in spherical particles of unity shape factor. The complete processing of the particle population was thus primary production, secondary coagulation for $<5 \% \mathrm{RH}$, exposure of agglomerates to an elevated variable RH for a controlled time period, and instrumental characterization of shape factors for $<5 \% \mathrm{RH}$. The final RH adjustment to $<5 \% \mathrm{RH}$ removed water from the particles, both serving to simplify interpretation of the sizing data of the DMA-APM and to freeze the particle shape after a controlled time period of possible material flow at elevated RH. This approach assumed that the particle shape did not change with rapid removal of water, as was reasonable considering the overall scenario of quick drying times relative to the slow material flow rates and the absolute water content of $<1 \%$ by volume.

Figure 3 represents the experimental strategy and expected results of the RH-dependent experiments in a diagram. For specific conditions (Fig. 3a), the production of dimer and trimer agglomerates of large shape factors was favored (leftmost to middle column). For non-optimized conditions, Fig. $3 b$ shows that coagulation events became sufficiently numerous that higher-order agglomerates were produced, resulting in particles of polyhedral shape and of correspondingly smaller shape factors. The middle-to-rightmost columns show the transition from aspherical to spherical particles after exposure to elevated RH for a sufficiently long time period.

In a series of RH-dependent experiments, aerosol particles produced from $700 \mathrm{pbb}$ of $\alpha$-pinene at ozone concentrations ranging from 14 to $30 \mathrm{ppm}$ were exposed stepwise to up to $80 \% \mathrm{RH}$ in a retention volume having an average residence time of $310 \mathrm{~s}$. The aerosol then flowed into a region of reduced $\mathrm{RH}(<5 \%)$, and $\chi$ values of selected diameter fractions were determined. Figure 4a shows the dependence of $\chi$ on RH for particle subpopulations having central mobility diameters of $126.0,175.0$, and $195.0 \mathrm{~nm}$. The respective $\chi$ values for $<5 \% \mathrm{RH}$ were $1.21 \pm 0.02,1.09 \pm 0.02$, and $1.08 \pm 0.02$ (one-sigma uncertainty), suggesting that the particle populations were composed largely of dimers and trimers in the first case and of higher-order agglomerates for

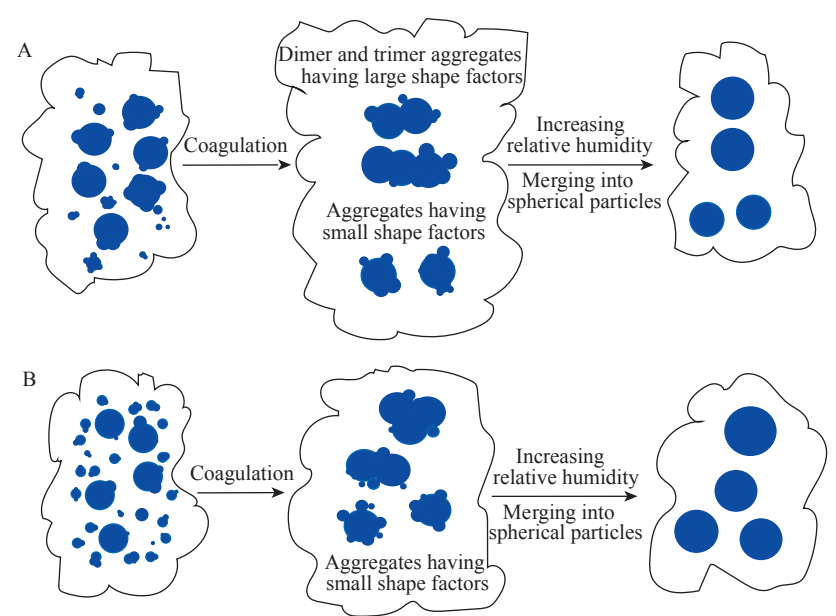

Figure 3. Diagram representing changes in particle shape due to coagulation and to elevated relative humidity. (a) Scenario for an experiment using a medium concentration of $\alpha$-pinene (700 ppb) in which two similarly sized particles collide to form dimer and trimer agglomerates, leading to relatively larger dynamic shape factors (rightmost to middle column). They constitute $<0.25 \%$ of the total particle population. They become nearly spherical after exposure to an elevated RH (middle to leftmost column). The elevated RH decreases viscosity and allows material flow. (b) Scenario for an experiment using a high concentration of $\alpha$-pinene (1000 ppb), in which several particles collide to form larger agglomerates having relatively smaller dynamic shape factors. At elevated $\mathrm{RH}$, these particles also flow and become spherical.

the latter two cases. The uncertainty estimate is based on repeated measurements. As the RH was increased, $\chi$ decreased for all three populations, reaching a final value of $1.02 \pm 0.01$ at $35 \% \mathrm{RH}$ and corresponding within uncertainty to spherical particles. The monotonic decrease in $\chi$ for increasing relative humidity implied a likewise monotonic decrease in viscosity. An alternative hypothesis of reactive chemistry with $\mathrm{H}_{2} \mathrm{O}$ for changing $\mathrm{RH}$ was not supported because the organic portion of the particle mass spectrum did not change upon exposure to elevated RH (Sect. S4).

Given that the extent of flow and hence the extent of shape change are expected to be tightly coupled to exposure time at elevated $\mathrm{RH}$, experiments were conducted to investigate the effect of exposure time on the observations. Figure $4 b$ shows results for a humidification time of $45 \mathrm{~s}$ compared to that of $310 \mathrm{~s}$. For an exposure time of $310 \mathrm{~s}$, the $\chi$ value of the selected 126-nm particles, which were identified by SEM as dimers (cf. Supplement, Sect. S4), decreased to unity by $35 \%$ RH. By comparison, for an exposure time of $45 \mathrm{~s}$, the $\chi$ value of the selected $165-\mathrm{nm}$ particles, which were identified by SEM as trimers, remained unchanged for $<5$ to $20 \% \mathrm{RH}$, decreasing to nearly unity only at $50 \% \mathrm{RH}$. The two curves were offset by approximately $20 \% \mathrm{RH}$. This result is consistent with the explanation that the shape change arose from material flow and that the flow required a finite amount of 

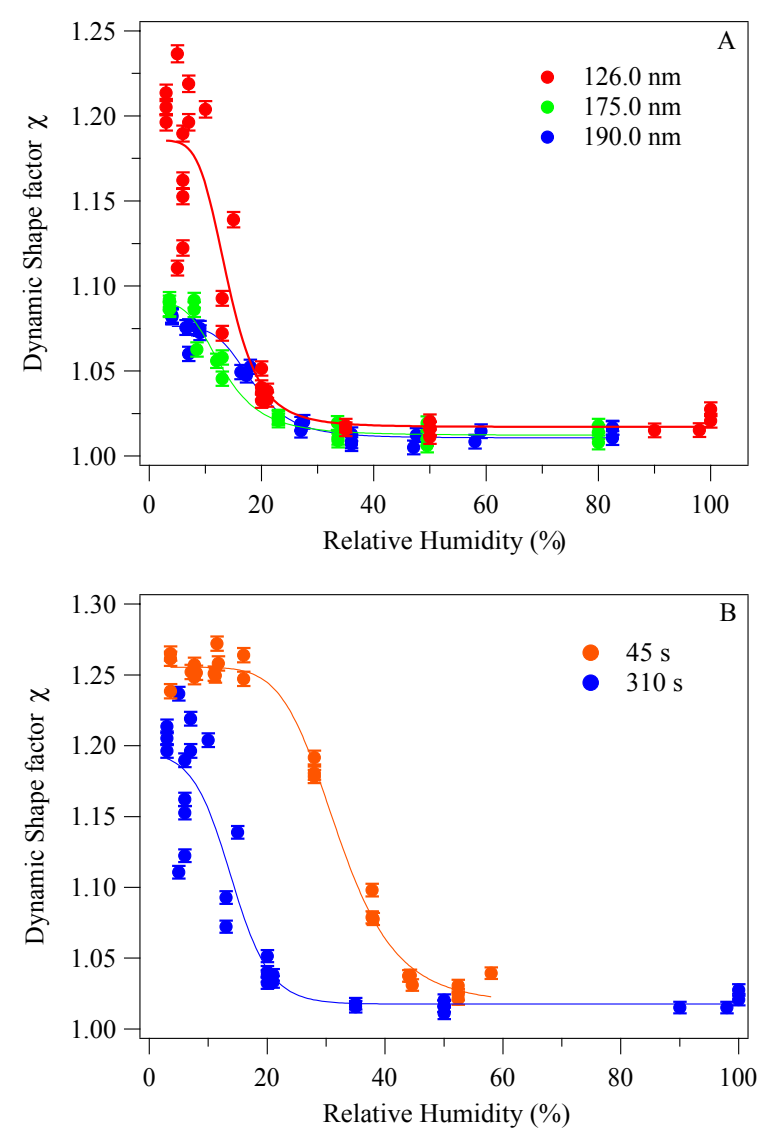

Figure 4. Dynamic shape factor for increasing relative humidity. (a) Particles produced from $700 \mathrm{ppb} \alpha$-pinene and 14, 25, and $30 \mathrm{ppm}$ ozone for particle populations having central mobility diameters of 126.0, 175.0, and $190.0 \mathrm{~nm}$, respectively. The exposure time to relative humidity was $310 \mathrm{~s}$. (b) Exposure up to $100 \% \mathrm{RH}$ for 45 or $310 \mathrm{~s}$. SOM was produced from $700 \mathrm{ppb} \alpha$-pinene and $14 \mathrm{ppm}$ ozone at $<5 \% \mathrm{RH}$. The error bars in each panel represent two sigma of standard deviation. The lines represent empirical fits to the data to guide the eye.

time to complete the full transformation to nearly spherical particles. A corollary is that the same extent of shape change at a shorter exposure time implies a decreased viscosity, all other factors being equal.

\subsection{Viscosity estimate}

The experimental results show a conversion from an aspherical to a nearly spherical shape within a specific time period, implying a rate of material flow and hence viscosity. The viscosity can therefore be estimated from the experimental results. To do so, a model was constructed using a commercial software package for numerical solutions to fluid flows (cf. Sect. S5). An example of the model simulation is shown in Fig. 5. A dimer consisting of two 90-nm diameter spheres having an overlap of $5 \mathrm{~nm}$ between the spheres was modeled for an exposure of $310 \mathrm{~s}$ to elevated RH (cf. Fig. S3). The

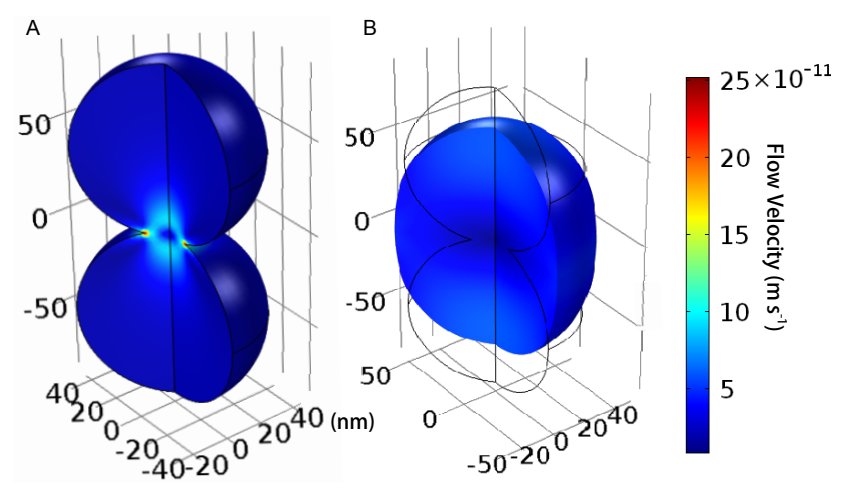

Figure 5. Flow simulation for the transformation of a dimer agglomerate into a spherical particle. (a) shows the initialization for $t=0 \mathrm{~s}$. Two monomers having a diameter of $45 \mathrm{~nm}$ and overlapping by $5 \mathrm{~nm}$ are shown. The coloring represents the instantaneous flow velocity. (b) shows the end of the simulation at $t=310 \mathrm{~s}$. The full time series is shown in film clip S1. The viscosity and its standard deviation, $(1.0 \pm 0.2) \times 10^{8} \mathrm{~Pa} \mathrm{~s}$, were optimized in the simulation so that the transformation from a dimer in (a) to a sphere in (b) was complete after $310 \mathrm{~s}$ (cf. data of Fig. $4 \mathrm{~b}$ and see also main text). In (b), the black lines represent the original shape of the particle (i.e., a).

two panels of Fig. 5 show the initial and final particle shapes (cf. film clip S1 in the Supplement). In $310 \mathrm{~s}$, the dimer transformed to a sphere for a viscosity of $(1.0 \pm 0.2) \times 10^{8} \mathrm{Pas}$, as obtained by numerical optimization. Please note that even though the RH was measured up to $100 \%$ in the experiment (cf. Fig. 4), the highest RH that could be studied (58\%) was limited by the full transformation to a spherical particle within the fastest experimental residence time ( $45 \mathrm{~s})$. An analytical result described in Frenkel (1945) for the full transformation of a dimer into a sphere leads to an estimated viscosity of $9.8 \times 10^{7} \mathrm{~Pa} \mathrm{~s}$, which is in good agreement with the numerical result. The numerical approach has the advantage that it can also be applied to partial transformations. The uncertainty estimate on the optimized value was based on a sensitivity analysis of the modeling results. A range of surface tensions, particle shapes (including extent of monomer overlap), and other factors was investigated (Sect. S6).

The example of Fig. 5 corresponds to the experimental results of Fig. $4 \mathrm{~b}$ showing the full transformation from $\chi$ of 1.21 for $<5 \%$ RH to $\chi$ of 1.02 for $35 \%$ RH in 310 s. Viscosities for other RH values were obtained by using the other data points of Fig. 4b, which corresponded to partial transformations. The results plotted in Fig. 6 show that the viscosity of $\alpha$-pinene SOM corresponded to a semisolid rather than a liquid to at least $58 \% \mathrm{RH}$. Part I represents data for changes in the shape factor data for a residence time of $310 \mathrm{~s}$. Part II represents data for $45 \mathrm{~s}$, for which a linear trimer consisting of $90-\mathrm{nm}$ spheres was modeled, again with an overlap of $5 \mathrm{~nm}$ between spheres. 


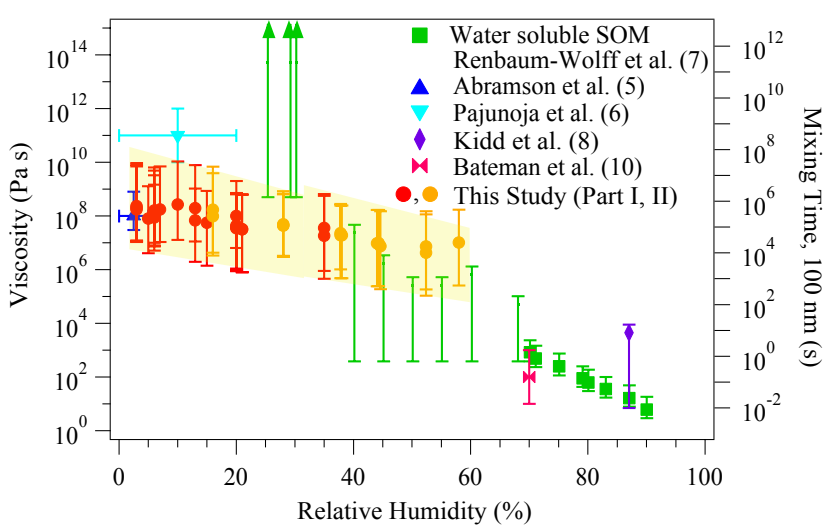

Figure 6. Summary of the RH-dependent viscosity obtained from this study for $\alpha$-pinene secondary organic material for $<5$ to $58 \%$ RH. The secondary $y$ axis shows the mixing time of low volatility molecules with an 100-nm particle. Part 1 represents data for changes in the shape factor for residence time of $310 \mathrm{~s}$ (cf. Fig. 4b). Part 2 represents data for $45 \mathrm{~s}$. The secondary $y$ axis shows the characteristic mixing time $\tau$ of low-volatility organic molecules due to bulk diffusion in 100-nm particles of the same viscosity. Results from literature are also plotted for comparison. A breakdown of the factors contributing to the uncertainty bars is presented in Fig. S13. Parts I and II also represent particle populations dominantly composed of dimer and trimer agglomerates, respectively.

For comparison, results from other experimental studies are also plotted in Fig. 6. The estimated viscosity for $<20 \% \mathrm{RH}$ agrees well with that of Abramson et al. (2013) and lies within the uncertainty of that of Pajunoja et al. (2013). Abramson et al. (2013) estimated the viscosity of $\alpha$-pinene SOM based on the evaporation rate of coincorporated pyrene from the particles at $<5 \% \mathrm{RH}$. Pajunoja et al. (2013) observed the shape of substrate-supported, submicron particles in vacuum by scanning electron microscopy and used the relaxation time of particle coalescence for $<30 \%$ RH to estimate viscosity. Kidd et al. (2014) estimated the viscosity of $\alpha$-pinene SOM by examining the deposition patterns of impacted particles at $87 \% \mathrm{RH}$. Bateman et al. (2015) observed a transition at $70 \%$ RH from rebounding to non-rebounding particles of $\alpha$-pinene SOM and calibrated this response as a transition in viscosity from 100 to 1 Pas (i.e., semisolid to liquid) based on the rebound behavior of sucrose particles of known viscosity. For comparison to the latter two studies of Kidd et al. and Bateman et al., the RH range of the present study was $<5$ to $58 \% \mathrm{RH}$. Renbaum-Wolff et al. (2013) measured the RH dependence of the viscosity of the water-soluble component of $\alpha$-pinene SOM by using optical microscopy to track the movement of small beads. The central values of the estimated viscosities of the present study are lower for $<30 \% \mathrm{RH}$ and higher for $>$ $40 \% \mathrm{RH}$, implying a reduced sensitivity of viscosity to $\mathrm{RH}$ for the present study compared to that reported for RenbaumWolff. These differences could relate to differences in sample preparation. Renbaum-Wolff et al. (2013) studied supermicron particles reconstituted from the water-soluble portion of SOM, which can be compared to the present experiments that studied whole SOM in aerosol form without post-processing. Given the differences in hygroscopicity and hence the volume fraction of water that can act as a plasticizer, the viscosity of the water-soluble portion of SOM can be expected to have greater sensitivity to RH than that of whole SOM.

The model used in the present study to estimate viscosity has several embedded assumptions. A surface tension of $5.5 \times 10^{-2} \mathrm{~N} \mathrm{~m}^{-1}$ was used to obtain local stress from local shape (Wex et al., 2009). This value is the average of 83 organic compounds (Korosi and Kovats, 1981). Diameter changes because of hygroscopic growth were taken as negligible for the studied RH range of $<5$ to $58 \% \mathrm{RH}$. A uniform value of viscosity throughout the particle was assumed, requiring that the uptake and diffusion of water throughout the particle was fast $(<1 \mathrm{~s})$ compared to the exposure times of 45 and $310 \mathrm{~s}$. This assumption is justified by observations of water uptake showing that submicron particles of $\alpha$ pinene SOM equilibrate with surrounding gas-phase water in less than $1 \mathrm{sec}$ (Smith et al., 2011). The diffusion coefficient of water in $\alpha$-pinene SOM for low to middle RH is above $10^{-13} \mathrm{~m}^{2} \mathrm{~s}^{-1}$ (Price et al., 2015), hence leading to a characteristic diffusion time $\tau$ throughout a $100-\mathrm{nm}$ particle of $\ll 1$ s (Shiraiwa et al., 2011). The model also assumed a specific exposure time (i.e., 45 or 310 s) to elevated $\mathrm{RH}$, whereas it was expected that the actual residence times of individual particles in the exposure flask had a distribution which approaches that of Poisson statistics at the limit of a continuously mixed flow reactor (Kuwata and Martin, 2012b).

\subsection{Implications}

Under the assumption that the concentration of a species in the gas phase maintains rapid equilibrium with its concentration in surface layer of a particle and in the absence of chemical reaction, the characteristic time $\tau$ to obtain a wellmixed particle by molecular diffusion is as follows (Seinfeld and Pandis, 2006):

$\tau=\frac{d^{2}}{4 \pi^{2} D}$

for particle diameter $d$ and molecular diffusion coefficient $D$. Use of Eq. (2) assumes that $D$ is uniform throughout the particle. With some limits to applicability (Price et al., 2014), the Stokes-Einstein equation relates the diffusion coefficient of a molecule within a host matrix of viscosity $\eta$, as follows (Lindsay, 2009):

$D=\frac{k T}{6 \pi r_{\mathrm{eff}} \eta}$

for Boltzmann constant $k$, temperature $T$, and effective radius $r_{\text {eff }}$ of the diffusing species. Combining Eqs. (2) and (3) 
Table 2. Viscosities of $\alpha$-pinene-derived secondary organic material at the lower and upper relative humidities of this study. Also shown are the characteristic mixing times for a diffusing species in a spherical SOM particle of $100 \mathrm{~nm}$. An effective radius of $1.5 \mathrm{~nm}$ is used. See main text for further explanation.

\begin{tabular}{lcc}
\hline $\begin{array}{l}\text { Relative } \\
\text { humidity }(\%)\end{array}$ & $\begin{array}{c}\text { Viscosity } \\
(\mathrm{Pas})\end{array}$ & $\begin{array}{c}\text { Characteristic } \\
\text { mixing time (day) }\end{array}$ \\
\hline$<5$ & $10^{(8.7 \pm 2.0)}$ & $10^{1.0 \pm 2.0}(11.5$ days $)$ \\
58 & $10^{(7.0 \pm 2.0)}$ & $10^{-0.68 \pm 2.0}(5.0 \mathrm{~h})$ \\
\hline
\end{tabular}

leads to the following expression for the characteristic mixing time:

$\tau=\frac{3 r_{\mathrm{eff}} \eta d^{2}}{2 \pi k T}$

For a case study, Table 2 lists mixing times obtained for a typical atmospheric particle diameter of $100 \mathrm{~nm}$ and for the viscosities of the present study for $<5$ and $58 \% \mathrm{RH}$ at $293 \mathrm{~K}$. Molecules such as $\mathrm{C}_{19-20} \mathrm{H}_{28-32} \mathrm{O}_{10-18}$, which correspond to a family of low-volatility molecules produced during $\alpha$ pinene ozonolysis, are considered for the case study (Ehn et al., 2014). The effective radius of this family is on order $1.5 \mathrm{~nm}$. The mixing times listed in Table 2 and Fig. 6 range from $5.0 \mathrm{~h}$ to 11.5 days for $<5$ to $58 \% \mathrm{RH}$, respectively. The SOM particles considered in the case study are, therefore, expected to reach equilibrium with the chemical composition of the gas phase rather slowly in some cases, especially in light of typical atmospheric residence times of 7 to 10 days. For $<5 \% \mathrm{RH}$, the characteristic mixing time can be more than a week, supporting the suggestion that chemical transport models significantly overestimate SOM particle mass concentration and underestimate gas-phase concentrations by assuming instantaneous chemical equilibrium between the two phases (Riipinen et al., 2011; Perraud et al., 2012). At $58 \% \mathrm{RH}$, the characteristic mixing time can approach several hours. The implication is that smaller molecules like ozone or water that diffuse faster in an SOM matrix than predicted by the Stokes-Einstein relationship might penetrate deeply into the particles, whereas organic molecules exchanged with the gas phase might be confined to the outer layer of the particle, thereby setting up a gradient in chemical composition and hence reactivity within the particle. The molecules at the surface in many cases might be kinetically determined rather than thermodynamically controlled, implying many non-surfactants at the surface.

The results of the present study can improve model estimates of gas uptake into particles and thereby improve model accuracy of particle growth rates and reactive processes. For low and intermediate $\mathrm{RH}$ and in the absence of a fast reaction, small molecules like $\mathrm{O}_{3}$ or $\mathrm{NO}_{x}$ are expected to diffuse rapidly to the center of atmospheric SOM particles, at least those in the Aiken and accumulation diameter modes and those represented well by $\alpha$-pinene SOM. Larger organic molecules, however, are expected to remain in the surface region of the particles for one or more days. Even so, the range of experimental conditions of a single study is necessarily limited, and future additional studies to track the variability of viscosity at higher RH and both warmer and cooler temperatures are well motivated. The viscosity of SOM generated from volatile organic compounds other than $\alpha$-pinene, as well as mixed chemical systems, also merits further investigation.

The scope of applicability of the approach introduced herein to determine viscosity of submicron particles in aerosol form can be considered. The lower limit for the RH that can be probed is related to the first discernible detection of shape change within the exposure time to elevated RH. In the present study, for $45 \mathrm{~s}$ of exposure, the lower limit of RH was $20 \%$. For $300 \mathrm{~s}$, the lower limit was $<5 \%$. The upper limit is related to the full transformation to a spherical particle within the exposure time to elevated RH. In the present study, for $45 \mathrm{~s}$ of exposure, the upper limit of RH was $58 \%$. For $300 \mathrm{~s}$, the upper limit was $25 \%$. The lower and upper limits for the viscosities that can be probed are related both to the particle diameter and the time for material flow (i.e., corresponding to the exposure time to elevated RH). For 100$\mathrm{nm}$ particles, viscosities as low as $10^{4} \mathrm{~Pa}$ and as high as $10^{12} \mathrm{Pas}$ for exposure times on order of $10 \mathrm{~s}$ and $10 \mathrm{~min}$, respectively, can be inferred by flow modeling to match shape changes. This viscosity range corresponds to varying degrees of semi-solidity. A future apparatus design for shorter residence times and larger particle diameters is an ongoing effort so that viscosity values can be probed at the transition point from semi-solidity to liquid. There might also be a limit on how small the non-liquid monomers can be, which were 20 to $40 \mathrm{~nm}$ in the present study and were coagulated to make the larger non-spherical particles; Cheng et al. (2015) have suggested that monomers on order $20 \mathrm{~nm}$ and smaller might be liquid.

In summary, the changing shapes of suspended submicron organic particles were monitored for $\mathrm{RH}$ exposures ranging from $<5$ to $58 \% \mathrm{RH}$ at $293 \mathrm{~K}$, and the characteristic times of the shape changes were used to estimate the RH-dependent viscosities of the constituent organic material. The viscosities decrease from $10^{(8.7 \pm 2.0)}$ to $10^{(7.0 \pm 2.0)} \mathrm{Pa} \mathrm{s}$ (two-sigma) as RH increases from $<5$ to $58 \%$ at $293 \mathrm{~K}$. The methodology developed in the present study of using the DMAAPM system to estimate viscosity for particles in situ as an aerosol, rather than being collected on a substrate for subsequent analysis, can avoid several potential artifacts specific to the semivolatile nature of SOM. If deployed for field measurements, the approach also has the promise of providing sufficient time resolution to track atmospheric variability.

\section{The Supplement related to this article is available online at doi:10.5194/acp-15-7819-2015-supplement.}


Acknowledgements. This material is based upon work supported by the National Science Foundation. We acknowledge Mona Shrestha, Yingjun Liu, and Irina Herdlinger-Blatt for useful discussions and assistance with the experiments.

Edited by: H. Su

\section{References}

Abramson, E., Imre, D., Beranek, J., Wilson, J., and Zelenyuk, A.: Experimental determination of chemical diffusion within secondary organic aerosol particles, Phys. Chem. Chem. Phys., 15, 2983-2991, doi:10.1039/C2CP44013J, 2013.

Agarwal, J. K. and Sem, G. J.: Continuous flow, single-particlecounting condensation nucleus counter, J. Aerosol Sci., 11, 343357, doi:10.1016/0021-8502(80)90042-7, 1980

Bateman, A. P., Bertram, A. K., and Martin, S. T.: Hygroscopic influence on the semisolid-to-liquid transition of secondary organic materials, J. Phys. Chem. A, 119, 4386-4395, doi:10.1021/jp508521c, 2015.

Biskos, G., Vons, V., Yurteri, C. U., and Schmidt-Ott, A.: Generation and sizing of particles for aerosol-based nanotechnology, KONA, 26, 13-35, doi:10.14356/kona.26.2008006, 2008.

Cappa, C. D. and Wilson, K. R.: Evolution of organic aerosol mass spectra upon heating: implications for OA phase and partitioning behavior, Atmos. Chem. Phys., 11, 1895-1911, doi:10.5194/acp11-1895-2011, 2011.

Cheng, Y., Su, H., Koop, T., Mikhailov, E., and Pöschl, U.: Size dependence of phase transitions in aerosol nanoparticles, Nat. Commun., 6, 5923, doi:10.1038/ncomms6923, 2015.

Donahue, N. M., Robinson, A. L., Stanier, C. O., and Pandis, S. N.: Coupled partitioning, dilution, and chemical aging of semivolatile organics, Environ. Sci. Technol., 40, 2635-2643, doi:10.1021/es052297c, 2006.

Ehara, K., Hagwood, C., and Coakley, K. J.: Novel method to classify aerosol particles according to their mass-to-charge ratio aerosol particle mass analyser, J. Aerosol Sci., 27, 217-234, doi:10.1016/0021-8502(95)00562-5, 1996.

Ehn, M., Thornton, J. A., Kleist, E., Sipila, M., Junninen, H., Pullinen, I., Springer, M., Rubach, F., Tillmann, R., Lee, B., Lopez-Hilfiker, F., Andres, S., Acir, I.-H., Rissanen, M., Jokinen, T., Schobesberger, S., Kangasluoma, J., Kontkanen, J., Nieminen, T., Kurten, T., Nielsen, L. B., Jorgensen, S., Kjaergaard, H. G., Canagaratna, M., Maso, M. D., Berndt, T., Petaja, T., Wahner, A., Kerminen, V.-M., Kulmala, M., Worsnop, D. R., Wildt, J., and Mentel, T. F.: A large source of low-volatility secondary organic aerosol, Nature, 506, 476-479, doi:10.1038/nature13032, 2014.

Fehsenfeld, F., Calvert, J., Fall, R., Goldan, P., Guenther, A. B., Hewitt, C. N., Lamb, B., Liu, S., Trainer, M., Westberg, H., and Zimmerman, P.: Emissions of volatile organic compounds from vegetation and the implications for atmospheric chemistry, Global Biogeochem. Cy., 6, 389-430, doi:10.1029/92GB02125, 1992.

Frenkel, J.: Viscous flow of crystalline bodies under the action of surface tension, J. Phys. USSR, 9, 385-391, 1945.

Hallquist, M., Wenger, J. C., Baltensperger, U., Rudich, Y., Simpson, D., Claeys, M., Dommen, J., Donahue, N. M., George,
C., Goldstein, A. H., Hamilton, J. F., Herrmann, H., Hoffmann, T., Iinuma, Y., Jang, M., Jenkin, M. E., Jimenez, J. L., Kiendler-Scharr, A., Maenhaut, W., McFiggans, G., Mentel, Th. F., Monod, A., Prévôt, A. S. H., Seinfeld, J. H., Surratt, J. D., Szmigielski, R., and Wildt, J.: The formation, properties and impact of secondary organic aerosol: current and emerging issues, Atmos. Chem. Phys., 9, 5155-5236, doi:10.5194/acp-9-51552009, 2009.

Hansson, H.-C. and Ahlberg, M. S.: Dynamic shape factors of sphere aggregates in an electric field and their dependence on the Knudsen number, J. Aerosol Sci., 16, 69-79, doi:10.1016/00218502(85)90021-7, 1985.

Hochrainer, D. and Hanel, G.: Der dynamische formfaktor nichtkugelförmiger teilchen als funktion des luftdrucks, J. Aerosol Sci., 6, 97-103, 1975.

Hoppel, W. A.: Determination of the aerosol size distribution from the mobility distribution of the charged fraction of aerosols, J. Aerosol Sci., 9, 41-54, doi:10.1016/0021-8502(78)90062-9, 1978.

Hosny, N. A., Mohamedi, G., Rademeyer, P., Owen, J., Wu, Y., Tang, M.-X., Eckersley, R. J., Stride, E., and Kuimova, M. K.: Mapping microbubble viscosity using fluorescence lifetime imaging of molecular rotors, P. Natl. Acad. Sci. USA, 110, 92259230, doi:10.1073/pnas.1301479110, 2013.

Kidd, C., Perraud, V., Wingen, L. M., and Finlayson-Pitts, B. J.: Integrating phase and composition of secondary organic aerosol from the ozonolysis of $\alpha$-pinene, P. Natl. Acad. Sci. USA, 111, 7552-7557, doi:10.1073/pnas.1322558111, 2014.

Knutson, E. O. and Whitby, K. T.: Aerosol classification by electric mobility: apparatus, theory, and applications, J. Aerosol Sci., 6, 443-451, 1975.

Korosi, G. and Kovats, E. S.: Density and surface tension of 83 organic liquids, J. Chem. Eng. Data, 26, 323-332, doi:10.1021/je00025a032, 1981.

Kousaka, Y., Endo, Y., Ichitsubo, H., and Alonso, M.: Orientationspecific dynamic shape factors for doublets and triplets of spheres in the transition regime, Aerosol Sci. Tech., 24, 36-44, doi:10.1080/02786829608965350, 1996.

Kuwata, M. and Kondo, Y.: Measurements of particle masses of inorganic salt particles for calibration of cloud condensation nuclei counters, Atmos. Chem. Phys., 9, 5921-5932, doi:10.5194/acp9-5921-2009, 2009.

Kuwata, M. and Martin, S. T.: Phase of atmospheric secondary organic material affects its reactivity, P. Natl. Acad. Sci. USA, 109 17354-17359, doi:10.1073/pnas.1209071109, 2012a.

Kuwata, M. and Martin, S. T.: Particle size distributions following condensational growth in continuous flow aerosol reactors as derived from residence time distributions: theoretical development and application to secondary organic aerosol, Aerosol Sci. Tech., 46, 937-949, doi:10.1080/02786826.2012.683204, 2012b.

Lindsay, S. M.: Introduction to Nanoscience, Oxford University Press, Oxford, 472 pp., 2009.

Loza, C. L., Coggon, M. M., Nguyen, T. B., Zuend, A., Flagan, R. C., and Seinfeld, J. H.: On the mixing and evaporation of secondary organic aerosol components, Environ. Sci. Technol., 47, 6173-6180, doi:10.1021/es400979k, 2013.

Pajunoja, A., Malila, J., Hao, L., Joutsensaari, J., Lehtinen, K. E. J., and Virtanen, A.: Estimating the viscosity range of SOA parti- 
cles based on their coalescence time, Aerosol Sci. Tech., 48, i-iv, doi:10.1080/02786826.2013.870325, 2013.

Perraud, V., Bruns, E. A., Ezell, M. J., Johnson, S. N., Yu, Y., Alexander, M. L., Zelenyuk, A., Imre, D., Chang, W. L., Dabdub, D., Pankow, J. F., and Finlayson-Pitts, B. J.: Nonequilibrium atmospheric secondary organic aerosol formation and growth, P. Natl. Acad. Sci. USA, 109, 2836-2841, doi:10.1073/pnas.1119909109, 2012.

Power, R. M., Simpson, S. H., Reid, J. P., and Hudson, A. J.: The transition from liquid to solid-like behaviour in ultrahigh viscosity aerosol particles, Chem. Sci., 4, 2597-2604, doi:10.1039/C3SC50682G, 2013.

Price, H. C., Murray, B. J., Mattsson, J., O'Sullivan, D., Wilson, T. W., Baustian, K. J., and Benning, L. G.: Quantifying water diffusion in high-viscosity and glassy aqueous solutions using a Raman isotope tracer method, Atmos. Chem. Phys., 14, 38173830, doi:10.5194/acp-14-3817-2014, 2014.

Price, H. C., Mattsson, J., Zhang, Y., Bertram, A., Davies, J. F., Grayson, J. W., Martin, S. T., O'Sullivan, D., Reid, J. P., Rickards, A. M. J., and Murray, B. J.: Water diffusion in atmospherically relevant $\alpha$-pinene secondary organic material, Chemical Science, doi:10.1039/C5SC00685F, 2015.

Renbaum-Wolff, L., Grayson, J. W., Bateman, A. P., Kuwata, M., Sellier, M., Murray, B. J., Shilling, J. E., Martin, S. T., and Bertram, A. K.: Viscosity of $\alpha$-pinene secondary organic material and implications for particle growth and reactivity, P. Natl. Acad. Sci. USA, 110, 8014-8019, doi:10.1073/pnas.1219548110, 2013.

Riipinen, I., Pierce, J. R., Yli-Juuti, T., Nieminen, T., Häkkinen, S., Ehn, M., Junninen, H., Lehtipalo, K., Petäjä, T., Slowik, J., Chang, R., Shantz, N. C., Abbatt, J., Leaitch, W. R., Kerminen, V.-M., Worsnop, D. R., Pandis, S. N., Donahue, N. M., and Kulmala, M.: Organic condensation: a vital link connecting aerosol formation to cloud condensation nuclei $(\mathrm{CCN})$ concentrations, Atmos. Chem. Phys., 11, 3865-3878, doi:10.5194/acp-11-38652011, 2011.

Robinson, E. S., Saleh, R., and Donahue, N. M.: Organic aerosol mixing observed by single-particle mass spectrometry, J. Phys. Chem. A, 117, 13935-13945, doi:10.1021/jp405789t, 2013.

Saleh, R., Donahue, N. M., and Robinson, A. L.: Time scales for gas-particle partitioning equilibration of secondary organic aerosol formed from alpha-pinene ozonolysis, Environ. Sci. Technol., 47, 5588-5594, doi:10.1021/es400078d, 2013

Seinfeld, J. H. and Pandis, S. N.: Atmospheric Chemistry Physics, John Wiley \& Sons, Hoboken, New Jersey, 2006.

Shiraiwa, M. and Seinfeld, J. H.: Equilibration timescale of atmospheric secondary organic aerosol partitioning, Geophys. Res. Lett., 39, L24801, doi:10.1029/2012GL054008, 2012.

Shiraiwa, M., Ammann, M., Koop, T., and Pöschl, U.: Gas uptake and chemical aging of semisolid organic aerosol particles, P. Natl. Acad. Sci. USA, 108, 11003-11008, doi:10.1073/pnas.1103045108, 2011.

Shiraiwa, M., Zuend, A., Bertram, A. K., and Seinfeld, J. H.: Gasparticle partitioning of atmospheric aerosols: interplay of physical state, non-ideal mixing and morphology, Phys. Chem. Chem. Phys., 15, 11441-11453, doi:10.1039/C3CP51595H, 2013a.

Shiraiwa, M., Yee, L. D., Schilling, K. A., Loza, C. L., Craven, J. S., Zuend, A., Ziemann, P. J., and Seinfeld, J. H.: Size distribution dynamics reveal particle-phase chemistry in organic aerosol formation, P. Natl. Acad. Sci. USA, 110, 11746-11750, doi:10.1073/pnas.1307501110, 2013b.

Shiraiwa, M., Berkemeier, T., Schilling-Fahnestock, K. A., Seinfeld, J. H., and Pöschl, U.: Molecular corridors and kinetic regimes in the multiphase chemical evolution of secondary organic aerosol, Atmos. Chem. Phys., 14, 8323-8341, doi:10.5194/acp-14-8323-2014, 2014.

Shrestha, M., Zhang, Y., Ebben, C. J., Martin, S. T., and Geiger, F. M.: Vibrational sum frequency generation spectroscopy of secondary organic material produced by condensational growth from $\alpha$-pinene ozonolysis, J. Phys. Chem. A, 117, 8427-8436, doi:10.1021/jp405065d, 2013.

Shrestha, M., Zhang, Y., Upshur, M. A., Liu, P., Blair, S. L., Wang, H., Nizkorodov, S. A., Thomson, R. J., Martin, S. T., and Geiger, F. M.: On surface order and disorder of $\alpha$ pinene-derived secondary organic material, J. Phys. Chem. A, doi:10.1021/jp510780e, 2014.

Slade, J. H., and Knopf, D. A.: Multiphase $\mathrm{OH}$ oxidation kinetics of organic aerosol: the role of particle phase state and relative humidity, Geophys. Res. Lett., 41, 5297-5306, doi:10.1002/2014GL060582, 2014.

Smith, M. L., Kuwata, M., and Martin, S. T.: Secondary organic material produced by the dark ozonolysis of $\alpha$ pinene minimally affects the deliquescence and efflorescence of ammonium sulfate, Aerosol Sci. Tech., 45, 244-261, doi:10.1080/02786826.2010.532178, 2011.

Vaden, T. D., Song, C., Zaveri, R. A., Imre, D., and Zelenyuk, A.: Morphology of mixed primary and secondary organic particles and the adsorption of spectator organic gases during aerosol formation, P. Natl. Acad. Sci. USA, 107, 6658-6663, doi:10.1073/pnas.0911206107, 2010.

Varutbangkul, V., Brechtel, F. J., Bahreini, R., Ng, N. L., Keywood, M. D., Kroll, J. H., Flagan, R. C., Seinfeld, J. H., Lee, A., and Goldstein, A. H.: Hygroscopicity of secondary organic aerosols formed by oxidation of cycloalkenes, monoterpenes, sesquiterpenes, and related compounds, Atmos. Chem. Phys., 6, 23672388, doi:10.5194/acp-6-2367-2006, 2006.

Virtanen, A., Joutsensaari, J., Koop, T., Kannosto, J., Yli-Pirila, P., Leskinen, J., Makela, J. M., Holopainen, J. K., Poschl, U., Kulmala, M., Worsnop, D. R., and Laaksonen, A.: An amorphous solid state of biogenic secondary organic aerosol particles, Nature, 467, 824-827, doi:10.1038/nature09455, 2010.

Wang, B., O’Brien, R. E., Kelly, S. T., Shilling, J. E., Moffet, R. C., Gilles, M. K., and Laskin, A.: Reactivity of liquid and semisolid secondary organic carbon with chloride and nitrate in atmospheric aerosols, J. Phys. Chem. A, 119, 4498-4508, doi:10.1021/jp510336q, 2014.

Wang, Z., King, S. M., Freney, E., Rosenoern, T., Smith, M. L., Chen, Q., Kuwata, M., Lewis, E. R., Pöschl, U., Wang, W., Buseck, P. R., and Martin, S. T.: The dynamic shape factor of sodium chloride nanoparticles as regulated by drying rate, Aerosol Sci. Tech., 44, 939-953, doi:10.1080/02786826.2010.503204, 2010.

Wex, H., Petters, M. D., Carrico, C. M., Hallbauer, E., Massling, A., McMeeking, G. R., Poulain, L., Wu, Z., Kreidenweis, S. M., and Stratmann, F.: Towards closing the gap between hygroscopic growth and activation for secondary organic aerosol: Part 1 - Evidence from measurements, Atmos. Chem. Phys., 9, 3987-3997, doi:10.5194/acp-9-3987-2009, 2009. 
Zelenyuk, A., Cai, Y., and Imre, D.: From agglomerates of spheres to irregularly shaped particles: determination of dynamic shape factors from measurements of mobility and vacuum aerodynamic diameters, Aerosol Sci. Tech., 40, 197-217, doi:10.1080/02786820500529406, 2006.

Zelenyuk, A., Imre, D., Beránek, J., Abramson, E., Wilson, J., and Shrivastava, M.: Synergy between secondary organic aerosols and long-range transport of polycyclic aromatic hydrocarbons, Environ. Sci. Technol., 46, 12459-12466, doi:10.1021/es302743z, 2012.
Zhou, S., Shiraiwa, M., McWhinney, R. D., Pöschl, U., and Abbatt, J. P. D.: Kinetic limitations in gas-particle reactions arising from slow diffusion in secondary organic aerosol, Faraday Discuss., 165, 391-406, doi:10.1039/C3FD00030C, 2013.

Zobrist, B., Soonsin, V., Luo, B. P., Krieger, U. K., Marcolli, C., Peter, T., and Koop, T.: Ultra-slow water diffusion in aqueous sucrose glasses, Phys. Chem. Chem. Phys., 13, 3514-3526, doi:10.1039/C0CP01273D, 2011. 